\title{
Identification of Meat Species by PCR-RFLP Method using Single Set of Degenerative Primers
}

\author{
Usman Asghar1*, Muhammad Faheem Malik ${ }^{1}$, Umer Rashid², Naeem Mahmood Ashraf ${ }^{2}$, Sumera Af- \\ sheen $^{1}$ and Muhammad Hashim ${ }^{1}$
}

${ }^{1}$ Department of Zoology, University of Gujrat, Hafiz Hayat campus, Punjab, Pakistan; ${ }^{2}$ Department of Biochemistry and Biotechnology, University of Gujrat, Hafiz Hayat campus, Punjab, Pakistan.

\begin{abstract}
Due to religious and social concerns, identification of meat and meat products is a matter of great interest for general public. DNA-based identification methods are ideal and reliable. DNA was extracted from muscle tissues of cow, buffalo, goat, donkey and a dog. A set of degenerative primers was designed for Polymerase Chain Reaction (PCR) of the cytochrome b gene fragment. All PCR was accomplished at the same reaction conditions. Amplified products had a length of $400 \mathrm{bp}$, which was our estimated length. After the sequencing of these amplicons, In silico restriction analysis was performed for each specie. Restriction endonuclease TfiI was selected for further analysis. Restriction fragment length polymorphism (RFLP) was performed at the same reaction conditions for all species. RFLP analysis produced species specific restriction profiles. Comparing these profiles, we have identified the species origin of meat unambiguously.

Received | July 06, 2020; Accepted | August 12, 2021; Published | November 30, 2021

*Correspondence | Usman Asghar,Department of Zoology,University of Gujrat,Hafiz Hayat campus,Punjab,Pakistan; Email:usmanasghar228@ gmail.com

Citation | Asghar, U., M.F. Malik, U. Rashid, N.M. Ashraf, S. Afsheen and M.hammad Hashim. 2022. Identification of meat species by PCRRFLP method using single set of degenerative primers. Sarhad Journal of Agriculture, 38(1): 188-194.

DOI | https://dx.doi.org/10.17582/journal.sja/2022/38.1.188.194

Keywords | Meat identification, DNA extraction, Degenerative primer, RFPL profiles, Restriction endonuclease
\end{abstract}

\section{Introduction}

Tn meat and meat products, animal species origin $\boldsymbol{I}$ is a great matter of concern, consumers demand accurate labelling of meat and its products (Ghovvati et al., 2009; Ballin, 2010). In Pakistan meat consumption is increasing rapidly; in 2000 it was only $11.7 \mathrm{~kg}$ per capita, currently it has reached $32 \mathrm{~kg}$ and is expected to reach $47 \mathrm{~kg}$ by 2020 (Sohaib and Jamil, 2017). In the past few years, several cases of meat adulteration and mislabeling were reported in Pakistan, dog meat mislabeled as goat and donkey meat mislabeled as cow or buffalo meat. Dog and donkey meat is prohibited in Pakistan due to religious as well as social issues (Zakaria, 2015). In such circumstances an easy and reliable method of labeling is required.
Numerous analytical techniques have been proposed for this labeling (Farag et al., 2015). An ideal analytical method should be rapid, specific, sensitive, reliable and economical (Matsunaga et al., 1999; Hsieh, 2000).

Electrophoresis, chromatography and enzyme-linked immunoassay are common analytical techniques (Hsieh, 2000; Floren et al., 2015). Different muscle proteins are separated by electrophoresis, but the requirement of baseline data and uniformity of protein patterns make their results elusive (Ilhak and Arslan, 2007). Chromatographic techniques differentiate among origin of meat by their fatty acid and protein composition (Chou et al., 2007), enzyme-linked immunoassay by reactivity of specific antibodies with 
muscles proteins (Rastogi et al., 2004). Storage, heat, pressure, salt treatment and adulteration with phylogenetically closed species can easily denature or alter the composition of protein and fatty acid and make these techniques less effective for stored, cooked, processed and adulterated meat samples (Choy et al., 2001).

These methods have been replaced by the DNA based methods because DNA has a conserved structure in all body cells and remains stable under pressure, heating and chemical processing (Rashid et al., 2014), and are effective for pure and adulterated meat samples. Randomly amplified polymorphic DNA (RAPD), polymerase chain reaction (PCR) with species-specific primers, nucleotide sequencing, real time PCR and Restriction fragment Length Polymorphism (RFLPs) are all DNA based methods for meat identification (Spychaj et al., 2009; Farag et al., 2015). RAPD and PCR with species-specific primers are laborious and need multiple primers. Sequencing and real time PCR are costly for routine meat identification (Rastogi et al., 2004). In some RFLP techniques, multiple primers and endonucleases are being used for differentiation among different type of meat (Lenstra et al., 2001). We used the RFLP method to contrive a simple diagnostic test for identification of meat origin among three commonly (cow, buffalo and goat) and two rarely (donkey and dog) used species in the meat industry of Pakistan. A single set of degenerative primers was designed and a single restriction enzyme was selected to reduce the time and expense of amplification and RFLP profiling.

\section{Materials and Methods}

\section{Sample collection}

Meat samples of cow (Bos taurus), buffalo (Bubalus bubalis) and goat (Capra bircus) were purchased from the Municipal slaughterhouse of district Gujrat of Punjab province, Pakistan. Meat samples of donkey (Equus asinus) and dog (Canis lupus) were collected from the government veterinary hospital of district Gujrat. All the samples were kept on ice and transferred to the refrigerating conditions, preserved at $-20{ }^{\circ} \mathrm{C}$ until the next step of DNA extraction.

\section{DNA extraction}

DNA was extracted from collected samples, by using organic phenol chloroform method (Musto, 2011) with slight modifications at its first step where after homogenizing $50 \mathrm{mg}$ of meat sample and addition of $500 \mu \mathrm{l}$ extraction buffer, sample was incubated for one hour at $37^{\circ} \mathrm{C}$ and with $15 \mu \mathrm{l}$ of proteinase $\mathrm{K}$ for overnight, following the other steps of phenol chloroform extraction method. At the end DNA pellet was air dried at room temperature for evaporation of remaining ethanol which was added at the last step. DNA pellet was dissolved in $50 \mu \mathrm{l}$ of ddH2O, DNA quality was measured by Qubit 3 fluorometer (ThermoFisher scientific) (Table 1), extraction confirmed in $2 \%$ agarose gel (1gm agarose in $50 \mathrm{ml} 1 \mathrm{X}$ TAE) ran at $80 \mathrm{~V}$ for 45 minutes. Following the completion of the process, extraction bands were visualized by UV light in transluminator (Biotec-Fischer) and used for PCR reaction.

Table 1: Quantity of DNA for goat (Capra hircus), dog (Canis lupus), cow (Bos taurus), buffalo (Bubalus bubalis) and donkey (Equus asinus), calculated by using Qubit 3 fluorometer and DNA quantity is presented in nanogram (ng) per microliter ( $\mu \mathrm{l}$ ) of ddH2O, used for dissolving the DNA pellet at the end of extraction.

$\begin{array}{ll}\text { Species name } & \text { DNA quantity } \\ \text { Goat } & 7.2 \mathrm{ng} / \mu \mathrm{l} \\ \text { Dog } & 1.2 \mathrm{ng} / \mu 1 \\ \text { cow } & 5.4 \mathrm{ng} / \mu \mathrm{l} \\ \text { buffalo } & 4.5 \mathrm{ng} / \mu 1 \\ \text { donkey } & 5.1 \mathrm{ng} / \mu \mathrm{l}\end{array}$

\section{PCR primers designing}

Complete cytochrome b gene, nucleotide sequence for five species were downloaded from the NCBI, Genbank database. BioEdit software was used to retrieve conserved region in the cytochrome $b$ gene.

The specific conserved region was located at two locations from 5'-373 to 383 -3' for universal forward primer and from 5'-755 to 773-3' for universal reverse primer. Region for forward primer had degeneracy at position $384(\mathrm{C}$ or $\mathrm{T}), 387$ ( $\mathrm{G}$ or $\mathrm{A}$ ) and 390 (C or A) and region for reverse primer had single degeneracy at $762(\mathrm{C}$ or $\mathrm{T})$ position. The oligonucleotide primer set was designed against such conserved sites to yield equal sized PCR products for all the five species under investigation. Primer properties were checked by using the OligoAnalyzer 3.1 (https://eu.idtdna.com/ calc/analyzer) calculator. Then this universal primer set (Table 2) was synthesized to use in PCR amplification against cytochrome $b$ gene to yield equal sized PCR fragments.

\section{Polymerase chain reaction (PCR)}

The PCR amplification master mix was prepared for 
Table 2: Degenerative primer set used for PCR amplification of cow (Bos taurus), buffalo (Bubalus bubalis) goat (Capra hircus) donkey (Equus asinus) and dog (Canis lupus), along with annealing temperatures, GC contents and expected $P C R$ product.

$\begin{array}{llllll}\text { Primer } & \text { Primer Sequence } & \text { Length } & \text { Temperature } & \text { GC Contents } & \text { PCR Product } \\ \text { Forward } & \text { 5'- GCC ACA GCA TTY ATR GGM TA-3' }^{\prime} & 20 & 58.1^{\circ} \mathrm{C} & 47.7 \% & 400-\mathrm{bp} \\ \text { Reverse } & \text { 5'- GGG GTG TAG TTY TCT GGG T-3' }^{\circ} & 19 & 56.1^{\circ} \mathrm{C} & 53.3 \% & \end{array}$

each specie separately, in $25 \mu 1$ reaction mixture containing, $1 \mu \mathrm{l}$ genomic DNA, $2 \mu \mathrm{l}$ Taq DNA polymerase, $0.5 \mu \mathrm{l}$ each forward and reverse primers, $2.5 \mu \mathrm{l}$ $\mathrm{MgCl}_{2}, 2.5 \mu \mathrm{l} 10 \mathrm{X}$ Taq buffer, $2 \mu \mathrm{dNTPs}$ and 14 $\mu \mathrm{l}$ distilled water. Three replicates were used for each species to measure variation in the experiment.

PCR amplification was performed, the first step is the initial denaturation at $94{ }^{\circ} \mathrm{C}$ for five minutes; $30 \mathrm{cy}$ cles; at $94{ }^{\circ} \mathrm{C}$ for 45 seconds, primer annealing at 52 ${ }^{\circ} \mathrm{C}$ for 45 seconds, elongation at $72{ }^{\circ} \mathrm{C}$ for one minute. After the completion of 30 cycles final elongation at $72{ }^{\circ} \mathrm{C}$ for 15 minutes. PCR amplification was performed at same conditions and by using a single degenerate primer set for all species. Successful amplification was confirmed by running PCR products on $2 \%$ agarose gel, at $70 \mathrm{~V}$ for 1 hour and visualizing under UV light in transluminator (Biotec-Fischer).

\section{Restriction analysis}

For restriction analysis, we sequenced our products and aligned the result of all the three replicates of each specie with each other by using software SeqMan.exe (DNASTAR) and checked the similarity index. We performed in silico restriction fragmentation for our amplified products. Restriction Mapper (http://www. restrictionmapper.org/) software was used for this analysis. Three restriction enzymes (TfiI, BseMII and TspDTI) were identified. These enzymes had restriction sites on different locations in $400 \mathrm{bp}$ fragment of cytochrome $b$ gene, which was amplified by our degenerative primer set. Among these restriction enzymes, TfiI was selected for further analysis, it implicated better and unambiguous results due to enough restriction site variability throughout the length of amplicon in each target specie. The reaction mixture was prepared containing $10 \mu \mathrm{l}$ unpurified PCR product (for all species separately), $4 \mu \mathrm{l} 1 \mathrm{X}$ enzyme buffer and 10 units TfiI enzyme. After incubation at $65^{\circ} \mathrm{C}$ for 3 hours, $\mathrm{PCR}$ restriction products were separated along with 100 bp DNA ladder (Thermo Fisher Scientific) in $3 \%$ agarose gel (1.5 gm agarose in $50 \mathrm{ml} 1 \mathrm{XTBE}$ ), which was run for 1.5 hours at $80 \mathrm{~V}$ and visualized with UV light, in transluminator (Biotec-Fischer).

\section{Results and Discussion}

\section{DNA extraction}

The extracted DNA were of fine quality and had good molecular weight, it was calculated by using Qubit 3 fluorometer and results are presented in table (Table 1). Only the dog DNA sample was of low quality (1.2 $\mathrm{ng} / \mu \mathrm{l})$, but it was clearly visible in the form of band in $2 \%$ agarose gel, along with other samples (Figure 1), and considered suitable for PCR amplification.

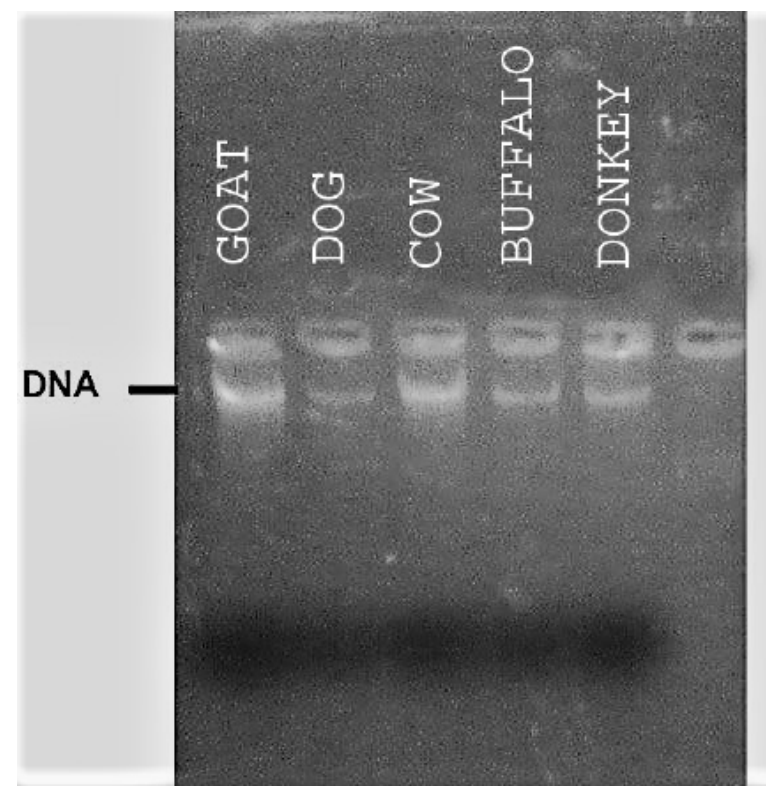

Figure 1: 2\% Agarose gel visualized in transluminator, all lanes from left to right containing the $D N A$, which was extracted from goat, dog, cow, buffalo and donkey by using phenol-chlorophorm method.

\section{Polymerase chain reaction ( $P C R)$}

PCR amplifications were performed with a single set of degenerative primers, and reaction conditions were the same for all species. Gel electrophoresis analysis showed that PCR amplification was successfully accomplished. The amplified product of cytochrome b gene belongs to five different species from left to right as goat, dog, cow, buffalo and donkey (Figure 2). All amplicons were perfectly of $400 \mathrm{bp}$ in length (Table 3) which was our expected product length, it was measured on the basis of their positions with respect to the bands position of $1 \mathrm{~kb}$ DNA ladder. 


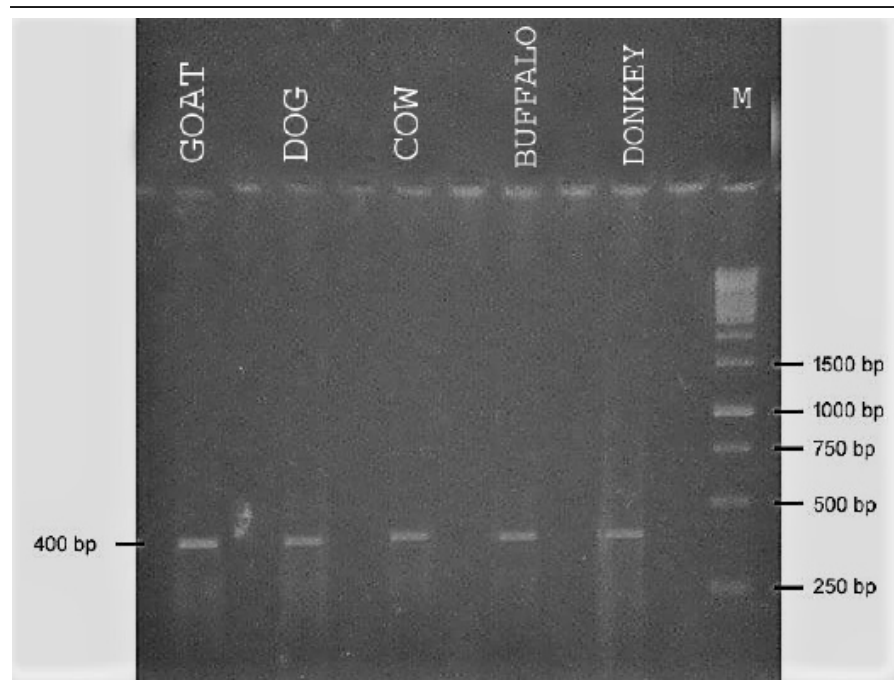

Figure 2: PCR amplification result of goat, dog, cow, buffalo and donkey, in all species cytochrome $b$ gene fragments have 400 bp length, $M$ represent the $1 \mathrm{~kb}$ ladder (Thermo Fisher).

Table 3: PCR product size, and species-specific fragments after RFLP of this 400bp amplicon for goat (Capra hircus), dog (Canis lupus), cow (Bos taurus), buffalo (Bubalus bubalis) and donkey (Equus asinus), with TfiI restriction endonuclease.

\begin{tabular}{lll} 
Specie & $\begin{array}{l}\text { PCR Product size } \\
\text { (bp) }\end{array}$ & $\begin{array}{l}\text { Fragments length in base } \\
\text { pairs (bp) }\end{array}$ \\
\hline Goat & 400 & $143,141,116$ \\
Dog & 400 & $194,107,99$ \\
Cow & 400 & $206,152,30,12$ \\
Buffalo & 400 & $164,107,99,30$ \\
Donkey & 400 & $152,129,107,12$
\end{tabular}

\section{Restriction fragmentation of amplicons}

Because we were treating three replicates for each species and after receiving the sequencing results, we aligned them by using software SeqMan.exe (DNASTAR) and confirmed that similarity index between the replicate was $>95 \%$. Three endonucleases BseMII, TfiI and TspDTI were selected after in silico analysis of sequence results of all species by Restriction Mapper software. TfiI endonuclease was found effective due to variation in restriction site along the length of all amplicons, and successfully generated species-specific restriction profiles for goat, dog, cow, buffalo and donkey respectively.

\section{RFLP profiling}

After restriction fragmentation by using TfiI, we obtained fragments having variable length for all species under investigation (Table 3). RFLP profile of both goat and dog have three restriction fragments indi- vidually, goat have 143-bp, 141-bp, 116-bp, while dog have 194-bp, 107-bp, 99-bp fragments. RFLP profile of cow, buffalo and donkey have four restriction fragments for each species separately. But length of fragments for each species is specific, cow have 206-bp, 152-bp, 30-bp, 12-bp, buffalo have 164-bp, 107-bp, 99-bp, 30-bp and donkey have 152-bp, 129-bp, 107bp, 12-bp fragments.

Gel electrophoresis analysis for restriction products for goat, dog, cow, buffalo and donkey along with 100-bp DNA ladder for estimation of product size (Figure 3) shows the variability in RFLP profiles. which make the differentiation between all the meat animals, easier, clearer and more explicit.

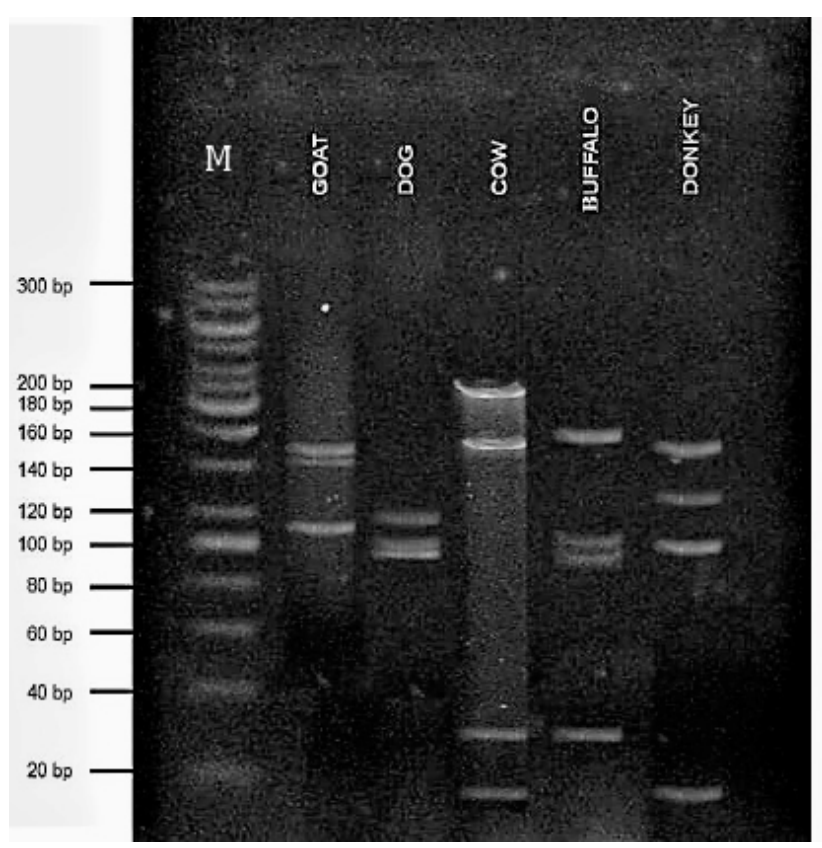

Figure 3: After the RFLP of 400bp amplified product with TfiI restriction enzyme, gel electrophoresis along with 100bp DNA ladder, give different length fragments of goat, dog, cow, buffalo and donkey, these RFLP profiles are species specific and helped to easily and unambiguously differentiate between them.

Amplification of a short region of a particular gene with enough variations is being used as a standard to identify species. It is easy to amplify, sequence and it is equally effective for damaged or diminutive samples. Mitochondrial genes are ideal for this purpose as they are present in all eukaryotes, conserved among the species and have high copy number in each cell (Kane and Hellberg, 2016).

In many previous studies, different mitochondrial genes, including D-loop region, $12 \mathrm{~S}$ and $16 \mathrm{~S}$ rRNA genes (Abdel-Rahman et al., 2009; Girish et al., 2004), cytochrome c as well as cytochrome b gene March 2022 | Volume 38 | Issue 1 | Page 191 
have been used for identification of meat specie origin, but most approaches were different from above mentioned technique.

These studies are focusing on identification of origin of different meat products or they tried to devised a diagnostic test for identification of some common meat species excluding dog and donkey. Wang et al. (2012) devised a diagnostic test for identification of twelve common meat species excluding donkey, they amplified the fragment of $12 \mathrm{~S}$ rRNA gene with double-fluorescently labeled primers which are quite expensive, and used capillary electrophoresis system which is not readily available in all molecular labs. For distinctive restriction profiling more than one restriction endonucleases (AluI and Tru9I) are required for this test (Wang et al., 2012).

Haider et al. (2012) amplified a fragment of cytochrome $\mathrm{c}$ oxidase subunit 1 (COI) gene with a single degenerative primer set and digested the amplicons with Hpa II restriction endonuclease to generate distinctive restriction profiles. But they investigated nine different meat species, excluding goat and dog and amplicons length was 710-bp (Haider et al., 2012), which is not more ideal for processed, cooked and stored meat samples due to fragmentation of DNA (Musto, 2011). Khan et al. (2018) amplified a very short fragment (359-bp) of cytochrome b gene for authentication of animal species. But they used more than one restriction endonucleases (Tas1, Hinf) for restriction profiling, and only considered the farm animals excluding dog and donkey meats (Khan et al., 2018).

As compared to the above-mentioned techniques, our approach is very simple and economical. We tried to address the real issue of meat adulteration and mislabeling with respect to Pakistani meat markets, and treat three commonly (cow, buffalo and goat) and two rarely ( $\mathrm{dog}$ and donkey) forbidden species. The equipment used in this experiment were of basic in nature and available in nearly all molecular labs. PCR amplification conditions and restriction analysis conditions are the same and can be performed with a single set of degenerative primers and single restriction endonuclease (TfiI) for all species under investigation. So now we are able to deal with any anonymous meat sample, if it belongs to any of these species.

Like all other DNA-based methods, our approach also requires DNA extraction from sample tissue, and this step limits its application on a large-scale practice. Further development of an easy and inexpensive extraction step shall make this method more feasible for mass testing and routine analysis (Hsieh et al., 2001).

\section{Conclusion and recommendations}

This work was designed as a test, to help the authorities to check the meat origin in the meat markets of Pakistan. Now we are able to identify the true origin of any meat sample with just three simple steps, DNA extraction, PCR amplification with degenerative primer and RFLP with the recommended restriction enzyme. Resulting RFLP profiles can compare with our given profiles to identify the origin of species.

\section{Acknowledgements}

We want to acknowledge Dr. Imran Bodla from PMAS-Arid Agriculture University Rawalpindi and two anonymous reviewers for their invaluable comments to improve our manuscript.

\section{Novelty Statement}

In this investigation we targeted the cytochrome $\mathrm{b}$ gene as marker gene for meat identification for the first time. We used single set of primers for PCR amplification and single restriction enzyme for RFLP of five different animal species under investigation.

\section{Authors Contribution}

Usman Asghar: Main investigator and contributed in all tasks.

Muhammad Faheem Malik and Umer Rashid: Performed supervision and conceptualization.

Naeem Mahmood Ashraf: Helped in primer designing and sequencing analysis.

SA and MH: Helped in formatting and proofreading. Umer Rashid, Naeem Mahmood Ashraf, Sumera Afsheen and Muhammad Hashim: Prepared the manuscript and reviewed it.

\section{Conflict of interset}

The authors declare no conflict of interest. 


\section{References}

Abdel-Rahman, S.M., El-Saadani, M.A., Ashry, K.M. and Haggag, A.S. 2009. Detection of adulteration and identification of cat's, dog's, donkey's and horse's meat using species-specific PCR and PCR-RFLP techniques. Aust. J. Basic Appl. Sci., 3: 1716-1719.

Ballin, N.Z. 2010. Authentication of meat and meat products. Meat Sci., 86(3): 577-587. https://doi.org/10.1016/j.meatsci.2010.06.001

Chou, C.C., Lin, S.P., Lee, K.M., Hsu, C.T., Vickroy, T.W. and Zen, J.M. 2007. Fast differentiation of meats from fifteen animal species by liquid chromatography with electrochemical detection using copper nanoparticle plated electrodes. J. Chromatogr. B., 846: 230-239.

Choy, Y.H., Oh, S.J. and Kang, J.O. 2001. Application of RAPD methods in meat for beef breed identification. Asian Aust. J. Anim. Sci. 14: 1655-1658.

Farag, M.R., Alagawany, M., Abd-El-Hack, M., Tiwari, R. and Dhama, K. 2015. Identification of different animal species in meat and meat products: trends and advances. Adv. Anim. Vet. Sci. 3(6): 334-346.

Floren, C., Wiedemann, I., Brenig, B., Schütz, E. and Beck, J. 2015. Species identification and quantification in meat and meat products using droplet digital PCR (ddPCR). Food Chem., 173: 1054-1058.

Ghovvati, S., Nassiri, M.R., Mirhoseini, S.Z., Moussavi, A.H. and Javadmanesh, A. 2009. Fraud identification in industrial meat products by multiplex PCR assay. Food control., 20(8): 696-699. https://doi.org/10.1016/j.foodcont.2008.09.002

Girish, P.S., Anjaneyulu, A.S.R., Viswas, K.N., Anand, M., Rajkumar, N., Shivakumar, B.M. and Bhaskar, S. 2004. Sequence analysis of mitochondrial 12S rRNA gene can identify meat species. Meat Sci., 66: 551-556.

Haider, N., Nabulsi, I. and Al-Safadi, B. 2012. Identification of meat species by PCR-RFLP of the mitochondrial COI gene. Meat Sci., 90: 490-493.

Hsieh, Y.H.P. 2000. Current development for the detection of meat species adulteration. In Proceedings $53^{\text {rd }}$ annual reciprocal meat conference. American Meat Science Association Champaign.
Hsieh, H.M., Chiang, H.L., Tsai, L.C., Lai, S.Y., Huang, N.E., Linacre, A. and Lee, J.C.I. 2001. Cytochrome $\mathrm{b}$ gene for species identification of the conservation animals. Forensic Sci. Int., 122: 7-18.

Ilhak, O.I. and Arslan, A. 2007. Identification of meat species by polymerase chain reaction (PCR) technique. Turkish J. Vet. Anim. Sci., 31: 159-163.

Kane, D.E. and Hellberg, R.S. 2016. Identification of species in ground meat products sold on the US commercial market using DNA-based methods. Food Contr., 59: 158-163.

Khan, W.A., Mustafa, H., Amir-u-Din, U., Yousaf, M., Ajmal, A., Mehmood, K. and Imran, M. 2018. Identification of species-specific molecular markers in different farm animals by PCRRFLP analysis. Pure Appl. Biol., 7: 338-342.

Lenstra, J.A., Buntjer, J.B. and Janssen, F.W. 2001. On the origin of meat-DNA techniques for species identification in meat products. Vet. Sci. Tomorrow., 2: 1-15.

Matsunaga, T., Chikuni, K., Tanabe, R., Muroya, S., Shibata, K., Yamada, J. and Shinmura, Y. 1999. A quick and simple method for the identification of meat species and meat products by $\mathrm{PCR}$ assay. 1999. Meat Sci., 51(2): 143-148. https:// doi.org/10.1016/S0309-1740(98)00112-0

Musto, M. 2011. DNA quality and integrity of nuclear and mitochondrial sequences from beef meat as affected by different cooking methods. Food Technol. Biotechnol., 49: 523-528.

Rashid, P.M.A., Babashekh, M.O., Marouf, A.S. and Amin, K.M. 2014. Identification of A animal Species in Meat Broth by Simplex and Multiplex PCR. J. Zankoy Sulaimani - Part A., 16: 97-102.

Rastogi, G., Dharne, M., Bharde, A., Pandav, V.S., Ghumatkar, S.V., Krishnamurthy, R., Patole, M. S. and Shouche, Y.S. 2004. Species determination and authentication of meat samples by mitochondrial 12S rRNA gene sequence analysis and conformation-sensitive gel electrophoresis. Curr. Sci., 87: 1278-1281.

Sohaib, M. and Jamil, F. 2017. An Insight of Meat Industry in Pakistan with Special Reference to Halal Meat: A Comprehensive Review. Korean J. Food Sci. Anim. Resour., 37(3): 329-333.

Spychaj, A. and Mozdziak, P.E. 2009. PCR methods in meat species identification as a tool for the verification of regional and traditional meat 
products. Acta Sci. Polon. Technol. Aliment., 8: 5-20.

Wang, Q., Zhang, X., Zhang, H.Y., Zhang, J., Chen, G.Q. and Zhao, D.H. 2010. Identification of 12 animal species meat by T-RFLP on the 12S rRNA gene. Meat Sci., 85: 265-269.

Zakaria, R. 2015. The real meat. Daily Dawn news 2015 Sep, 16. https://www.dawn.com/ news $/ 1207254$ 